\title{
Predicting Business Failure for Malaysia SMEs in the Hospitality Industry
}

\author{
Juraini Zainol Abidin ${ }^{1, *}$ Nur Adiana Hiau Abdullah ${ }^{2}$ Karren Lee-Hwei Khaw ${ }^{3}$
}

\author{
1,2 Universiti Utara Malaysia \\ 3 University of Malaya \\ *Corresponding author: diana897@uum.edu.my
}

\begin{abstract}
SMEs are an important segment of the Malaysian economy and contribute significantly to the country's economic growth. Nonetheless, SMEs are riskier and associated with a high failure rate. Hence, the aim of this study is to develop a failure prediction model for SMEs in the hospitality industry by using the logit and artificial neural network (ANN) approach for 82 SMEs over the period 2000 to 2016. The findings show that the ANN model predicts better than the logit model in both the estimation and holdout sample with a predictive accuracy rate of $98.2 \%$ and $92 \%$, respectively, while the logit model provides overall accuracy rates of $86 \%$ and $80 \%$, respectively. This study also finds that both models identify return on assets and board size as an important signal of business failure. The models could be used to assist investors, creditors and lenders to screen out failing SMEs, and the authorities could decide on policies to improve SMEs in the hospitality industry.
\end{abstract}

Keywords: Business Failure, Hospitality Industry, SMEs

\section{INTRODUCTION}

SMEs are important to the economy of every country. Malaysia is no exception as SMEs make up $98.5 \%$ of the total business establishments and $65 \%$ of the total workforce [1]. Despite the challenging environment, they continue to expand at a faster pace than the overall economy. In 2016, the SMEs recorded a Gross Domestic Product (GDP) growth of $5.2 \%$, resulting in an increase in the SME contribution to $36.6 \%$ of the country's GDP [2]. The GDP growth of SMEs was mainly supported by strong tourism activity and domestic demand [2].

Although the tourism industry is identified as one of the major sources of foreign exchange receipts and contributes significantly to the country's economic growth [2], businesses within this industry are exposed to relatively high failure rate. In the United Kingdom, an average of $13.4 \%$ of businesses in the accommodation and restaurant fail each year from 2012 to 2017 [3]. In Malaysia, around $3.5 \%$ of SMEs fail within two years and $54 \%$ cease operations within four years [4]. If a large number of these SMEs fail, it would negatively affect the Malaysia's economy. In this sense, a business failure prediction model would be an important early warning tool to signal potentially distressed SMEs so that corrective measures could be taken to mitigate potential business failure. Thus, the aim of this study is to model SMEs failure in the hospitality industry of Malaysia.

To date, most of the published works on the hospitality industry are implemented for public listed or large companies $[5,6,7,8,9,10,11,12,13,14]$. Only recently, Pacheco [15] conducts a bankruptcy study for SMEs in the hospitality industry of Portugal. Studies that model small business failure in Malaysia focus on the manufacturing sector $[16,17]$. Thus far, there is lack of research in modeling business failure in the hospitality industry in Malaysia, which instigates us to look into this topic.

The rest of the paper is organized as follows: Section 2 provides a review of literature, Section 3 discusses the methodology, Section 4 presents the empirical results and the final section concludes the paper.

\section{LITERATURE REVIEW}

A few modelling techniques are used to predict the likelihood of business failure. Among the earliest works are the studies by Beaver [18] who uses univariate analysis, followed by Altman [19], who employs multiple discriminant analysis (MDA), Ohlson [20] who introduces logit analysis and Odom and Sharda [21] who utilises the ANN. 
The first study that focuses on SMEs is Edmister [22] by using MDA to forecast the loan default of the US small businesses. His model achieves an overall accuracy rate of $93 \%$. However, the assumptions behind MDA, such as normality, linearity and equal variance in the failed and non-failed firms are often violated [23]. Hence, other statistical approaches, such as logit and probit analyses have been proposed as alternatives to the MDA. The benefit of using the logit technique is that it can handle non-linear relationships [24]. This method has resulted in a conditional probability model that consists of a combination of variables that best discriminate between a failed firm and a non-failed firm.

Considering the limitation of MDA, Altman and Sabato [24] employ a logit technique to forecast the failure rate of the US SMEs. The overall classification rate of the model is $87.22 \%$ in the holdout sample.

Although the logit method does not require the dependent and independent variables to be linearly related, it requires that the independent variables are linearly related to the 'logit' function (a ratio of the odds of success to the odds of failure) [25]. Otherwise the test underestimates the strength of the relationship and rejects the relationship easily, that is being not significant where it should be significant [25]. Therefore, there is a need for a method that relaxes the requirements on the data, in contrast to the linear methods.

ANN model is less stringent to the assumptions as compared to traditional statistical techniques [26]. A major advantage of the ANN technique is that its ability to recognize patterns regardless of the functional form of the relationship [27]. As such, it has the ability of expressing non-linear relationships and has the ability to adaptively adjust the model Sung, et al. [28]; thus, it is claimed that it can predict business failure better than the MDA and logit models [10, 29, 30, 31]. In bankruptcy prediction studies, the ANN model is first employed by Odom and Sharda [20] to compare the predictive power of the ANN model to Altman's (1968) MDA model. The ANN model outperforms the MDA, in which ANN accurately forecasts $81.48 \%$ of the bankrupt firms in the holdout sample, but the MDA model could only accurately predict $59.26 \%$ of the bankrupt firms in the holdout sample.

In line with the above studies, there is a number of empirical research which utilizes and compares different methods to identify the most appropriate technique to predict failure $[10,12,13,26,33,34,35,36]$. Some studies find that ANN model performs better than linear models [10, 31, 37, 38, 56]. Utilizing a sample of companies in diverse range of business sectors, Khermkhan and Chancharat [31] analyze the accuracy of various techniques in forecasting Thai SMEs for the year 2011 and 2012. Results indicate that the ANN model consistently outperforms the MDA, logit and probit models, with a correct classification rate of $85 \%, 71.6 \%$, $72.8 \%$ and $62.2 \%$, respectively.

On the contrary, some studies find that the ANN model does not always resulted in better performance than the MDA and logit models [26, 36, 39, 40]. Sayeh and Bellier [36] develop failure prediction models for French SMEs in various sectors using the ANN and logit model. The results show that the logit model yields a better accuracy rate than the ANN with a classification accuracy rate of $74.8 \%$ and $71.1 \%$ respectively.

As for the hospitality industry, only a few studies are conducted to predict failure in this industry. Most of the published works focus on public listed or large companies [6, 7, 8, 9, 10, 26]. Pacheco [15] employs a logit technique to predict failure for 460 Portugal SMEs in the hotel and restaurant business over the period 2004 to 2014. Results show that debt to total assets and equity to total assets are significant in explaining business failure. The accuracy rate is only $68.7 \%$.

\section{METHODS}

The sample used in this study consists of failed and healthy SMEs in the hospitality industry, particularly accommodation and restaurants. The sample is collected from the Companies Commission of Malaysia (CCM) database for the period 2000 to 2016. SMEs with a Malaysia Standard Industrial Classification (MSIC) codes of 5510 (short terms accommodation activities which refer to hotels and resort hotels, motels and apartment hotels) and 5610 (restaurants and food service activities) are selected. Out of this list, 312 companies that were declared bankrupt are randomly identified. After removing companies with incomplete information, the final sample comprises of 41 for each failed and healthy SMEs that is matched based on the same sub-industry and have a similar total asset plus minus 10\%. Data for two years prior to winding-up is used for the analysis because most of the failed SMEs do not submit their financial statements when companies are nearing bankruptcy. This led to a small sample size one year prior to failure. Seventy percent of the sample is utilized for model estimation and the remaining thirty percent is used as a holdout sample to test the predictive power of the developed models. Financial data and non-financial information of these SMEs are obtained from the CCM database. SME is defined as companies that are having annual sales up to RM20 million, as adopted by the National SME Development Council (SME Corporation, 2013). Failed SMEs are defined as those being wound up by court order or creditors request under Section 218 (1)(e) and (2) of the Companies Act 1965.

Two models are employed, i.e., logit and ANN. Logit incorporates non-linear effects and the coefficients are estimated based on the cumulative logistic function to predict failure. The estimates for the coefficients are performed through maximum likelihood method, which 
maximizes the probability of classifying the observed data into the appropriate category. A cut-off value of 0.50 is employed to differentiate between a failed and a healthy SME. SME is classified as failed if $P$ value equals to or greater than 0.50 and it is classified as healthy if $\mathrm{P}$ value less than 0.50 .

The logit regression functional form is as follows:

$\mathrm{P}=1 /\left(1+\mathrm{e}^{\wedge}\left(-\left(\alpha+\beta \_1 \mathrm{X} \_1+\beta \_2 \mathrm{X} \_2+\cdots+\beta \_\mathrm{n} \mathrm{X} \_\mathrm{n}\right)\right)\right.$ )$=1 /\left(1+\mathrm{e}^{\wedge}(-\mathrm{y})\right)$

Where $\mathrm{P}$ is the probability of failure, $\quad \beta \_n$ are parameter estimates of the model and $X_{-} n$ are the predictor variables which are: current assets to current liabilities [41, 42, 43, 44]; total liabilities to total assets and total liabilities to total equity (Abdullah et al., 2016a, 2016b; Charalambakis, 2014; Goo and Shih, 2015; Pacheco, 2015; Ciampi and Gordini, 2008); net income to total assets and net income to sales [17, 24, 41, 42, 49]; sales to total assets $[47,48]$; firm size (total assets) and firm age [16,17, 44, 49, 54]; ownership concentration [45]; board size and board diversity [17, 42, 45]. Since there is no theoretical foundation for selecting potential variables [29], the variables identified in this study are based on the ratios used in previous studies and data availability in the CCM database.

The second model to predict failure is ANN which consists of processing elements or nodes that are connected into a network by a set of weights [26]. This paper used multilayer perceptron (MLP) network [45, 50] which can be mathematically presented as [51]:

$$
\mathrm{y}=\mathrm{f} 2(\mathrm{w} 2 \mathrm{f} 1(\mathrm{w} 1 \mathrm{x}+\mathrm{b}))
$$

In the MLP network, $y$ is the output, $x$ comprises of financial, non-financial and governance variables (as in the logit model) as the input layer, $\mathrm{b}$ is a bias, w1 and w2 are matrices that link the weights from input to hidden layer and from hidden to output layer, and $\mathrm{f} 1$ and $\mathrm{f} 2$ are the transfer functions for the respective hidden node and output node. The selection of the transfer function depends on the nature of the output. Since the network output lies between 0 and 1 , which represents the probability of failure, an appropriate transfer function is logistic or sigmoid transfer function. The sigmoid transfer function with an output node $y$ is expressed as:

$$
y=f(x)=1 /\left(\left(1+e^{\wedge}(-x)\right)\right)
$$

Sigmoid non-linearity takes a real valued number and "squashes" it into range between 0 and 1 . $\mathrm{f}$ is the output of the perceptron neurons (hidden node and output node) and $\mathrm{x}$ is the weighted sum of the input synapses. For a binary classification problem, only one output node is required to represent the group membership. Thus, in this study, SMEs with output value greater than 0.50 is classified as failed; otherwise it would be classified as non-failed.

\section{RESULTS AND DISCUSSIONS}

significantly lower than that of healthy SMEs, while debt ratio of failed SMEs is significantly higher than that of healthy SMEs. The lower liquidity and higher gearing of failed SMEs directly influenced their profitability as return on assets and net income to sales exhibited negative and lower values than those of healthy SMEs. This is also reflected in the sales to total assets in which the results show that failed SMEs are less efficient than the healthy SMEs. As a result of negative earnings over the years, the failed SMEs would eventually end up with negative net worth and this is reflected in a negative debtequity ratio of failed SMEs. As for non-financial variables, age is found to be significant in differentiating between failed (10 years) and healthy SMEs (12 years), but size is not. Furthermore, it is found that healthy SMEs have larger board size than failed SMEs, which concurs to the study of [17].

Pearson correlation reveals that the correlations among the variables are relatively low except for return on assets against debt ratio. To ensure there is no multicollinearity problem, a variance inflation factor (VIF) is analyzed. VIF for all variables is less than 10, ranges from 1.222 to 3.125 indicating that multicollinearity is not a problem to this study.

Table 1 presents the stepwise logistic regression results. The Hosmer-Lemeshow statistic shows that the model fits the data since the test value is insignificant at the 0.05 level. Two variables are found to be significant determinants of failure, namely ROA and board size. The coefficient for ROA shows a negative sign, which suggests that SMEs with lower profitability would experience a higher probability of failure. This indicates that failed SMEs lack the abilities to generate profit out of each dollar of sales. Kim (2018) suggests that generating adequate cash flow is critical for the hospitality industry to service debt given the nature of this industry is capital-intensive. The results of this study are consistent to Abdullah et al. [16, 17], Altman et al. [41], Bredart [42], Ciampi and Gordini [44], Terdpaopong [48], Wellalage and Locke [49], and Yazdanfar and Nilsson [52] that record a negative relationship. Board size is also found to be a significant predictor. A negative relationship between board size and the probability of SME failure reveals that a company with larger board is less likely to fail because there are more people on the board with more experience, expertise and connections. The finding of this study concurs with Abdullah et al. [16], and Keasey and Watson [53]. 
Table 1. Estimated Logistic Regression Model

\begin{tabular}{|l|c|c|c|}
\hline \multicolumn{1}{|c|}{ Variable } & Category & Coefficient & Change in -2 Log Likelihood \\
\hline ROA & Financial & -12.422 & 33.408 \\
\hline & & & $(0.000)^{\star * *}$ \\
\hline Board size & Governance & -1.169 & 5.768 \\
\hline & & & $(0.016)^{\star \star}$ \\
\hline Constant & & 3.441 & \\
\hline & & $(0.035)$ & \\
\hline Hosmer and Lemeshow test & & 5.158 & \\
\hline$* *$ : significant 5\% & & $(0.741)$ & \\
\hline
\end{tabular}

*** $\quad$ : significant $1 \%$

As for the logit model accuracy rates, $82.8 \%(91.7 \%)$ and $89.3 \%(69.2 \%)$ of the failed and healthy SMEs could be correctly classified for the estimation (holdout) sample. The overall classification rate of the model in the estimation and holdout sample is $86.0 \%$ and $80.0 \%$, respectively. The logit model in this study predicts better than the logit model of Pacheco [15].

For comparison purposes, the MLP neural network model is employed using the same data set as in the logit model. A sensitivity analysis is performed on the 11 independent variables to measure the importance of each variable in building the network. Youn and Gu [13] suggest that a variable importance value of more than 0.10 is used to identify a significant indicator of failure as it indicates that the variable has the greatest effects on the prediction. Five input variables are found to be significant indicators of failure as their value are more than 0.10 , namely current ratio, net income to sales, total liabilities to total equity, ROA and board size. Hence, this study develops the MLP neural network model with five input variables to predict the failure of SMEs in the hospitality industry.

Based on the findings, it appears that financial variables, i.e. current ratio, net income to sales, ROA and total liabilities to total equity, as well as governance variable, i.e. board size contribute significantly in building the network. The liquidity positions of failed SMEs are low as a result of poor business performance. Consequently, they would have limited cash to run the business and fulfil their debt obligations, which would eventually drive them into bankruptcy. This is supported by Bredart [41], Ciampi and Gordini [33], and Lugovskaya [54]. Results also show that failed SMEs are operating at a loss as they are unable to generate sufficient profits to support business operations, thus increases the default risk. The finding is consistent with Gu [8], Lugovskaya [54], Sirirattanaphonkun and Pattarathammas [55], Khermkan and Chancharat [31], Stroie [56], Wellalage and Locke [44], and Yazdanfar and Nilsson [52].

Debt-equity ratio is found to be high for healthy SMEs, with an average of 1.25 times, but negative for failed SMEs, indicating that companies in the hospitality industry have been relying on debt to support operation rather than getting the fund from the owners. This variable is ranked the third most important variable to predict failure with a normalized importance of 88 percent. The finding is consistent with Kim [10] who finds that Korean hotels rely heavily on debt as the proportion of debt is larger than owners' equity. Hence, debt-burdened hotels with poor profitability are more likely to be potential bankruptcy candidates such as seen in this study. In another study, Kim [11] argues that highly leveraged hospitality firms that are not accompanied with optimum net profit margin are likely to be in financial distress and eventually would go bankrupt.

The MLP neural network model accurately classifies $100 \%(91.7 \%)$ of failed SMEs and $96.4 \%(92.3 \%)$ of healthy SMEs in the estimation (holdout) sample, bringing an overall accuracy rate of $98.2 \%$ (92\%) respectively. The findings of this study show that the MLP model outperforms the logit model in both the estimated and holdout samples. This is consistent with the findings of Youn and Gu [26] and Khermkhan and Chancharat [31].

Both the logit and MLP models select ROA and board size as important factors that could discriminate between a failed and a non-failed SME, indicating that other than financial variables, governance attributes are also important to forecast failure. Since ROA is selected by both models, it becomes an important early warning signal for SMEs failure in the hospitality industry. For SMEs to survive in this industry, they should efficiently utilize company assets to generate profit. Additionally, hospitality companies need more members on the board that could provide more views and links to the external environment, as well as offer an extensive choice of possible solutions for the company's survival. It could also be observed that in addition to company's profitability, the MLP model also stresses on the liquidity and leverage as the main indicators of failure. 


\section{CONCLUSION}

This study attempts to develop and to compare the performance of the MLP model against the logit model by using a sample of 41 failed SMEs matched with 41 healthy SMEs in the hospitality industry from 2000 to 2016. Results show that the MLP model gives a higher prediction accuracy rate for both the estimation and holdout samples than the logit model. In terms of the failure indicators, both models identify ROA and board size as important determinants that could differentiate between a failed and a non-failed SME. In addition, the MLP model identifies other variables as main indicators of failure, i.e. current ratio, debt to equity ratio and net income to sales. Creditors, regulators and investors should consider the MLP prediction model as it provides a more accurate and reliable assessment of the company's financial status. An effective failure prediction model could reduce economic losses to the affected parties by providing signals that would enable them to take preventive measures to possible adverse situations..

\section{REFERENCES}

[1] Department of Statistics, Economic census 2016: Profile of small and medium enterprises, Putrajaya: Department of Statistics, Malaysia, 2016.

[2] SME Corporation, SME annual report 2016/17, Kuala Lumpur: SME Corporation Malaysia, 2017.

[3] Office for National Statistics, Statistical bulletin: business demography, UK: 2017, United Kingdom, 2018.

[4] S. H. A. Shah, A. R. M. Ali, Entrepreneurship (2nd ed.), Shah Alam, Malaysia: Oxford Fajar Sdn Bhd, 2011.

[5] A.A. Barreda, Y. Kageyama, D. Singh, S. Zubieta, Hospitality bankruptcy in United States of America: A multiple discriminant analysis-logit model comparison, Journal of Quality Assurance in Hospitality \& Tourism, vol. 18(1), 2017, pp. 86106.

[6] M. Á. Fernández-Gámez, A. J. Cisneros-Ruiz, A. Callejon-Gil, Applying a probabilistic neural network to hotel bankruptcy prediction, Tourism \& Management Studies, vol. 12(1), 2016., pp. 40-52.

[7] G. Gemar, I. P. Soler, V. F. Guzman-Parra, Predicting bankruptcy in resort hotels: a survival analysis, International Journal of Contemporary Hospitality Management, 2019.

[8] Z. Gu, Analyzing bankruptcy in the restaurant industry: A multiple discriminant model, International Journal of Hospitality Management, vol. 21(1), 2002, pp. 25-42.
[9] H. Kim, Z. Gu, A logistic regression analysis for predicting bankruptcy in the hospitality industry, The Journal of Hospitality Financial Management, vol. 14(1), 2006, pp.17-34.

[10] S. Y. Kim, Prediction of hotel bankruptcy using support vector machine, artificial neural network, logistic regression, and multivariate discriminant analysis, The Service Industries Journal, vol. 31(3), 2011, pp.441-468.

[11] S. Y. Kim, Predicting hospitality financial distress with ensemble models: the case of US hotels, restaurants, and amusement and recreation, Service Business, vol. 12(3), 2018, pp.483-503.

[12] S.-S. Park, M. Hancer, A comparative study of logit and artificial neural networks in predicting bankruptcy in the hospitality industry, Tourism Economics, vol. 18(2), 2012, pp. 311-338.

[13] H. Youn, Z. Gu, Predict US restaurant firm failures: The artificial neural network model versus logistic regression model, Tourism and Hospitality Research, vol. 10(3), 2010, pp. 171-187.

[14] S-S. Zhai, J-G. Choi, F. Kwansa, A financial ratiobased predicting model for hotel business failure, Global Business \& Finance Review, vol. 20(1), 2015, pp. 71-86.

[15]L. Pacheco, SMEs probability of default: The case of the hospitality sector, Tourism \& Management Studies, vol. 11(1), 2015, pp. 153-159.

[16] N. A. H. Abdullah, A. H. Ahmad, N. Zainudin, R. Md Rus, Modelling small and medium-sized enterprises failure in Malaysia, International Journal of Entrepreneurship and Small Business, vol. 28(1), 2016, pp. 101-116.

[17] N. A. H. Abdullah, M. M. Ma'aji, K. L. H. Khaw, The value of governance variables in predicting financial distress among small and medium-sized enterprises in Malaysia, Asian Academy of Management Journal of Accounting \& Finance, vol. 12 (Suppl. 1), 2016, pp. 77-91.

[18] W. H. Beaver, Financial ratios as predictors of failure, Journal of Accounting Research, 4 (Supplement), 1966, pp. 71-111.

[19] E. I. Altman, Financial ratios, discriminant analysis and the prediction of corporate bankruptcy, The Journal of Finance, vol. 23(4), 1968, pp. 589-609.

[20] J. A. Ohlson, Financial ratios and the probabilistic prediction of bankruptcy, Journal of Accounting Research, 1980, pp. 109-131.

[21] M. D. Odom, R. Sharda, A neural network model for bankruptcy prediction, Proceedings of 
International Joint Conference on neural networks, 1990, pp.163-168.

[22] R. Edmister, An empirical test of financial ratio analysis for small business failure prediction, Journal of Financial and Quantitative Analysis, vol. 7(2), 1972, pp. 1477-1493.

[23] S. Balcaen, H. Ooghe, Alternative methodologies in studies on business failure: Do they produce better results than the classical statistical methods, (Working Paper No. 4/249). Gent, Belgium: Faculty of Economy, Ghent University. 2004.

[24]E. I. Altman, G. Sabato, Modelling credit risk for SMEs: Evidence from the U.S. market, Abacus, vol. 43(3), 2007, pp. 332-357.

[25]D. Schreiber-Gregory, Logistic and linear regression assumptions: violation recognition and control, Paper presented at the SAS Conference Proceedings: Western Users of SAS Software, Sacramento, California, 2018.

[26]H. Youn, Z. Gu, Predicting Korean lodging firm failures: An artificial neural network model along with a logistic regression model, International Journal of Hospitality Management, vol. 29(1), 2010, pp. 120-127.

[27] A. Charitou, E. Neophytou, C. Charalambous, Predicting corporate failure: Empirical evidence for the UK, European Accounting Review, vol. 13(3), 2004, pp. 465-497.

[28] T. K. Sung, N. Chang, G. Lee, Dynamics of modeling in data mining: interpretive approach to bankruptcy prediction, Journal of Management Information Systems, vol. 16(1), 1999, pp. 63-85.

[29] B. Back, T. Laitinen, K. Sere, M. van Wezel, Choosing bankruptcy predictors using discriminant analysis, logit analysis, and genetic algorithms, (Technical Report No. 40). Turku, Finland: Turku Centre for Computer Science, 1996.

[30] A.M. Dima, S. Vasilache, Credit risk modeling for companies default prediction using neural networks, Romanian Journal for Economic Forecasting, vol. 19(3), 2016, pp.27-143.

[31] J. Khermkhan, S. Chancharat, Failure forecasting in Thai SME's: The comparative of the MDA, logit, probit models and ANN, Proceedings of the Asian Business \& Management Conference, 2013, pp.2533.

[32]F. Ciampi, N. Gordini, Using economic-financial ratios for small enterprise default prediction modeling: An empirical analysis, Proceedings of
Oxford Business \& Economics Conference Oxford UK, vol 1, 2008, pp. 1-21.

[33]F. Ciampi \& N. Gordini, The potential of corporate governance variables for small enterprise default prediction modeling: Statistical evidence from Italian manufacturing firms: Preliminary findings, Proceedings of Cambridge Business \& Economics, 2013, pp.1-19.

[34] M. Hernandez Tinoco, N. Wilson, Financial distress and bankruptcy prediction among listed companies using accounting, market and macroeconomic variables, International Review of Financial Analysis, vol. 30, 2013, pp. 394-419.

[35] N. Mselmi, A. Lahiani, T. Hamza, Financial distress prediction: the case of French small and mediumsized firms, International Review of Financial Analysis, vol. 50, 2017, pp. 67-80.

[36] W. Sayeh, A. Bellier, Neural network versus logistic regression: the best accuracy in predicting credit rationing decision, SSRN Electronic Journal, 2014 [doi: 10.2139/ssrn.2513730].

[37] R. C. Lacher, P. K. Coats, S. C. Sharma, L. F. Fant, A neural network for classifying the financial health of a firm, European Journal of Operational Research, vol. 85(1), 1995, pp. 53-65.

[38] R. Sharda, R. L. Wilson, Neural network experiments in business-failure forecasting: predictive performance measurement issues, International Journal of Computational Intelligence and Organization vol. 1, 1996, pp.107-117.

[39]E. I. Altman, G. Marco, F. Varetto, Corporate distress diagnosis: Comparisons using linear discriminant analysis and neural networks (the Italian experience), Journal of Banking \& Finance, vol. $18(3), 1994$, pp. 505-529.

[40] J. Boritz, D. Kennedy, A. Albuqereque, Predicting corporate failures using a neural network approach, Intelligent Systems in Accounting, Finance and Management, vol. 4(2), 1995, pp. 95-111.

[41]X. Bredart, Bankruptcy prediction model using neural networks, Accounting and Finance Research, vol. 3(2), 2014, pp.124-128.

[42]F. Ciampi, N. Gordini, Small enterprise default prediction modeling through artificial neural networks: An empirical analysis of Italian small enterprises, Journal of Small Business Management, vol. 51(1), 2013, pp. 23-45.

[43] S. Gunawidjaja, B. Hermanto, Default prediction model for SME's: Evidence from Indonesian market using financial ratios (Research Paper No. 
13-04). Graduate School of Management, University of Indonesia. 2010.

[44] N. H. Wellalage, S. Locke, Factors affecting the probability of SME bankruptcy: A case study on New Zealand unlisted firms, Business Journal for Entrepreneurs (Quarterly), 2012, pp. 1-17.

[45]F. Ciampi, Corporate governance characteristics and default prediction modeling for small enterprises. An empirical analysis of Italian firms, Journal of Business Research, vol. 68(5), 2015, pp. 1012-1025.

[46]E. C. Charalambakis, Corporate financial distress prediction: What can we learn from private firms in a small open economy? (Working Paper No. 188). Greece: Bank of Greece, 2014..

[47] Y.-J. Goo, A.-Y. Shih, Impact of credit guarantee on the survival of SMEs and default prediction for SMEs: Empirical evidence from Taiwan, Proceedings of International Council for Small Business (ICSB), Dubai, UAE, 2015, pp.1-20.

[48] K. Terdpaopong, D. G. Mihret, Modelling SME credit risk: A Thai empirical evidence, Small Enterprise Research, vol. 18(1), 2011, pp. 63-79.

[49]E. I. Altman, G. Sabato, N. Wilson, The value of non-financial information in small and mediumsized enterprise risk management, Journal of Credit Risk, vol. 6(2), 2010, pp. 1-33.

[50] A. Blanco-Oliver, A. Irimia-Dieguez, M. OliverAlfonso and N. Wilson, Improving bankruptcy prediction in micro-entities by using nonlinear effects and non-financial variables, Czech Journal of Economics and Finance, vol. 65(2), 2015, pp. 144-166.
[51] G. Zhang, M. Y. Hu, B. E. Patuwo, D. C. Indro, Artificial neural networks in bankruptcy prediction: General framework and cross-validation analysis, European Journal of Operational Research, vol. 116(1), 1999, pp.16-32.

[52]D. Yazdanfar, M. Nilsson, The bankruptcy determinants of Swedish SMEs, Proceedings of ISBE International Entrepreneurship ConferenceBelfast, Ireland, 2008, pp. 1-14.

[53] K. Keasey, R. Watson, Non-financial symptoms and the prediction of small company failure: A test of Argenti's hypotheses, Journal of Business Finance \& Accounting, vol. 14(3), 1987, pp. 335354.

[54] L. Lugovskaya Predicting default of Russian SMEs on the basis of financial and non-financial variables, Journal of Financial Services Marketing vol. 14, 2010, pp. 301-313.

[55] W. Sirirattanaphonkun, S. Pattarathammas, Default prediction for small-medium enterprises in emerging market: Evidence from Thailand, Seoul Journal of Business, vol. 18(2), 2012, pp. 25-54.

[56] L. M. B. Stroie, Techniques for customer behaviour prediction: A case study for credit risk assessment, Proceedings of International Conference on New Techniques and Technologies for Statistics Eurostat, Brussels, 2013, pp. 685-694.

[57] M. Modina, F. Pietrovito, A default prediction model for Italian SMEs: The relevance of the capital structure, Applied Financial Economics, vol. 24(23), 2014, pp.1537-1554. 